\title{
The Impact of Socially Responsible Investing in European Markets: Evidence of the Global Financial Crisis
}

\author{
Irene Guia Arraiano*
}

\begin{abstract}
The increasing global importance of the environmental, social and economic aspects and the high complexity of their implications at the corporate level is the reason for an intense and extensive research activity, leading Socially Responsible Investing to a current and prominent theme, namely in Europe. In this context, this study analyses the effects of Socially Responsible Investing on portfolio performance of all listed firms on the ten most important European stock markets over the period 2001-2013 rated by the Global Reporting Initiative. In order to measure the portfolios' performance, a market model and a four-factor model are applied in which risk factors were constructed for the markets under study. A relevant finding of the present study is that investing in this type of firms before the financial crisis was less risky than investing afterwards, as it presented to be riskier. Nevertheless, investing in socially responsible firms which had a higher profitability in the past outperforms the market. However, the results show the existence of market singularities across European countries that must be considered, as well as the periods of pre and post global financial crisis that affected the European stock markets, triggered the sovereign debt crisis, especially in peripheral countries.
\end{abstract}

Keywords: European stock markets, Socially Responsible Investing, Global Reporting Initiative, performance, risk, financial crisis.

\section{Introduction}

Socially Responsible Investing (SRI) has increasingly attracted the attention of several entities worldwide. It is a subject that interests the business world on both the political and governmental areas, and its development is also of interest to the stakeholders. Nowadays the concern for SRI is a current subject, but it is not new, in fact, it has existed since the $12^{\text {th }}$ century ${ }^{1}$. Nevertheless, it was from the 1990 s that the world's largest expansion occurred with the creation of the Domini Social Investments index. Progressively, firms and societies started to be aware of the importance of sustainable development and its evolution, as it is proven by the KPMG (2015) and Eurosif (2014).

Over the years, as SRI became an important factor in the financial markets, a new question has arisen: "Is there any economic and financial virtue to invest in Socially Responsible (SR) firms?". To answer this much debated question, the relationship between corporate social responsibility and corporate financial performance has been

1 Since $12^{\text {th }}$ century due to Jewish traditions, as well as Christian and Islamic, according to Renneboog (2008). 
studied as documented by Revelli and Viviani (2015), and Wang et al. (2016).

According to Wallis \& Klein (2015) the empirical studies that cover SRI in Europe have not been extensive. The existing literature mainly focuses on the UK because it has the longest history of SRI and the most developed market. The present study aims to contribute to discover the differences in SRI between European countries which have not been analysed until today.

This study differs from the existing literature in several aspects. Firstly, it uses all listed firms in the ten most prominent countries in Europe. Secondly, it relates CSR performance to financial performance for both the full sample and the comparison among the ten countries. Thirdly, the main contribution is the application of the Carhart (1997) four-factor model in which risk factors are constructed for the entire sample and also for each of the stock markets individually. Thus, this study differentiates from most by using the risk factors available in Kenneth French Data Library. Finally, the global financial crisis caused a turmoil in the European stock markets and this study determines the main consequence in terms of risk-adjusted return to the SRI, and analyses the influence of the risk factors.

The remainder of the article is organized as follows. The literature review is described in section 2. The section 3 presents the database and risk factors used in this research. The methodology proposed to measure stock performance of socially responsible firms is described in section 4. Section 5 reports the empirical results and section 6 the conclusions.

\section{Literature Review}

The existing literature concentrates mostly on the relationship between corporate social responsibility and financial performance (Griffin \& Mahon, 1997). There are indications that companies which engage in socially responsible and sustainable practices outperform in certain contexts (Waddock \& Graves,1997; Kempf \& Osthoff, 2007).

However, Galema et al. (2008) applied the Carhart (1997) model and found no significant differences in risk-adjusted return. Statman and Glushkov (2009) analysed the returns of SR firms, excluding the ones related to tobacco, alcohol, gambling, firearms, and nuclear operations in the period 1992-2007, and concluded that there is an advantage of SRI over conventional firms. Hong and Kacperczyk (2009) obtained better results in the same market in the period between 1962 and 2006, although it is of great importance to mention that in this case the authors included in the portfolio the companies that deal with alcohol, tobacco, and gambling, which have a higher return when compared with the remaining listed firms. Still for the North American market, Derwall et al. (2011) noted the great controversy between investors who practice SRI and those who do not, who are called "SIN". By using the information published in the KLD database, they applied the Fama-French (1993) and Carhart (1997) models by using these two data samples. Trinks and Scholtens (2017) investigated the impact of negative screening on the investment universe, as well as on the financial performance, for more than twenty years. The empirical results suggest that the choice for negative screening strategies does matter not only for the size of the investment universe, but also for the risk-adjustment 
return performance.

The number of studies on SRI in European markets is further reduced because of the lack of available information. Humphrey et al. (2012), and Brzeszczynski and McIntosh (2014) investigated the performance of SR portfolios in the United Kingdom (UK) consisting of firms listed both in the Dow Jones Sustainable Index and in the Most Sustainable Corporations in the World. The results differ indicating that the criteria for selecting the SR firms are crucial. The risk factors of the multifactorial model were estimated, and the authors conclude that the risk-adjusted return can only be explained by the market factor.

More recently, Mollet and Ziegler (2014) investigated the markets of North America and Europe by applying the Carhart's multifactor model (1997). Consequently, the results obtained were negative for the small minus big factor in both regions, and the winners minus losers' factor is negative for the three portfolios in Europe. The risk-adjusted return was not statistically significant in both markets with respect to SRI, although this type of investment is not penalised in the European and US markets. The authors conclude that the size factor influences the results obtained. For the Spanish market, Miralles-Marcelo et al. (2012) constructed SR portfolios and applied a multifactorial model. The results obtained led to the conclusion that in subperiods of economic recession, SRI is safer compared to periods of economic expansion.

The methodologies used and the variables considered in each study as well as the study periods differ, which explains not only the heterogeneity of the results obtained, but also the difficulty found in the comparison of the conclusions.

\section{Data and Risk Factors}

\subsection{Data}

To begin with, it is necessary to define which firms are SR in each of the stock markets. There are several private companies that provide information regarding social responsibility. KPMG (2015) research shows that the Global Reporting Initiative (GRI) remains the most popular voluntary disclosure guideline worldwide and is also used by the world's largest firms ${ }^{2}$.

To carry out this study, the social responsibility information according to the GRI available annually was considered, and the stock exchange information database was obtained from the Thomson Reuters DataStream. Therefore, the research analyses all firms listed $(2,015)$ on the stock markets of the ten European countries - Denmark (42), Finland (124), France 480), Germany (466), Italy (136), the Netherlands (112), Norway (45), Spain (93), Sweden (57) and the United Kingdom (460) in the period from January 2001 to December 2013. The remaining European markets were excluded from the study due to the fact that the number of listed firms included in GRI was limited, such as in Ireland and Portugal.

The financial information comprises the monthly prices on each of the stock exchanges

2 The GRI since 1999 annually prepares and publishes a listing with the classification obtained by a large number of international and global firms after evaluating each one according to the sustainability guidelines, and the information provided is of great importance for the investors. 
considered. The market value, price to book value and three-month risk-free rate (Euribor - 3 months) were also extracted. Nevertheless, it should be noted that this study excludes the banking sector and insurance firms, because they have a specific accounting system different from other sectors.

As it is shown in Graph1 below, we can observe the number of firms listed and rated by GRI in the ten European stock markets investigated in the present study ${ }^{3}$, from 2001 to 2013. We can see the increasing trend in the number of SR firms in each of the European stock markets, in which the UK leads the ranking. It is worth noting a marked decrease in the year 2013. It is possible that this decline follows the introduction of the GRI G4 framework which could be considered more complex than the previous GRI framework as it includes anti-corruption and gender policies (KPMG, 2015).

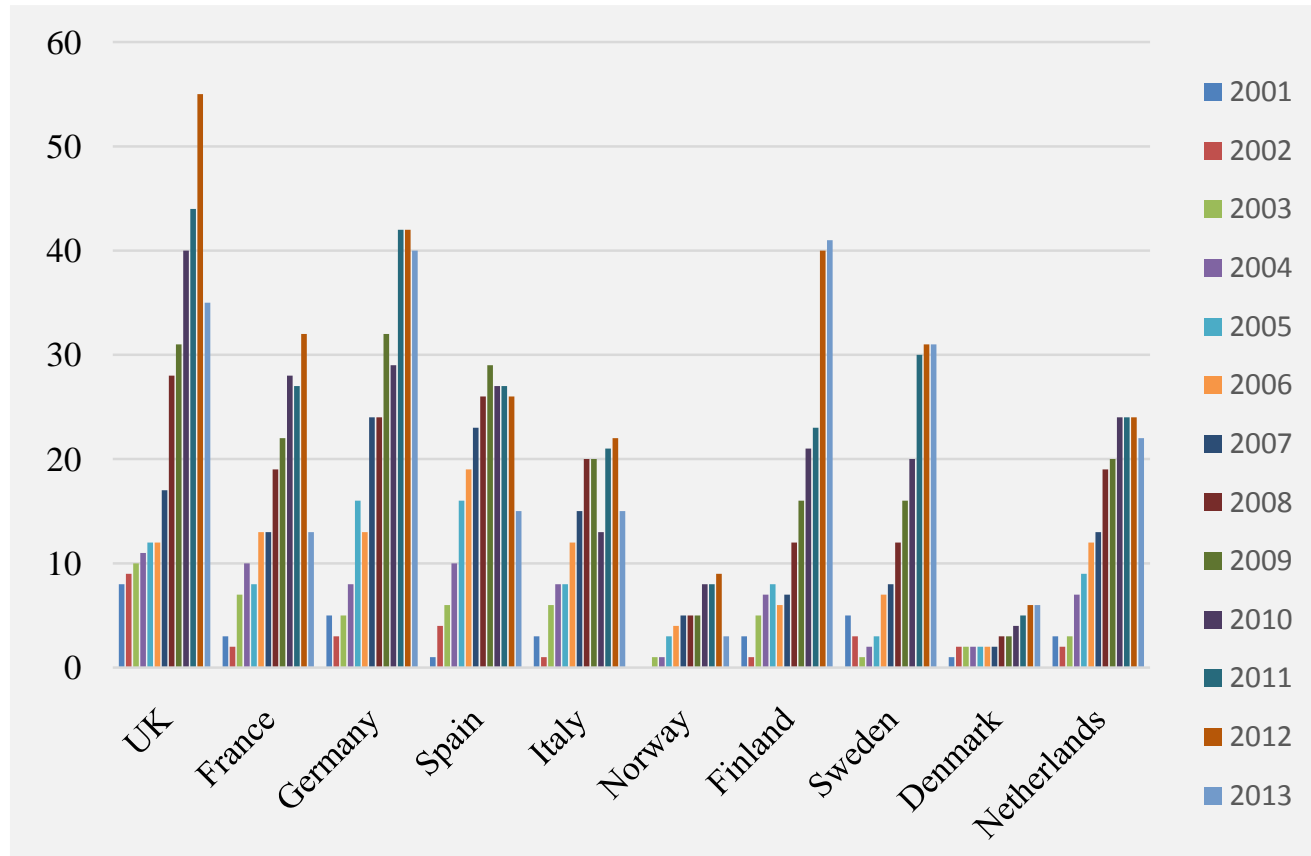

Graph 1: Disclosure evolution by market according GRI (2001-2013)

Source: Global Reporting Initiative and DataStream Database. Own elaboration.

\subsection{Factors}

For the construction of the proxy for the market portfolio, all stocks listed in the last day of each month were considered. The GRI portfolio is formed annually by selecting the firms classified in this social responsibility rating for all the markets as a whole, and also for each stock market individually.

The risk factors of the Fama-French (1993) and Carhart (1997) models Small Minus Big (SMB), High Minus Low (HML) and Winners Minus Losers (WML) are constructed

\footnotetext{
${ }^{3}$ The Tables with the information of the firms that have been rated annually by GRI, by stock market, are available upon request.
} 
annually. On the last stock exchange, dated June of each year, the information was extracted regarding which firms were listed in their respective stock markets, and excluded the firms of the financial sector. Subsequently, all the stocks were ranked based on size, and the bottom $50 \%$ of total market capitalization was assigned to the small portfolio (S). The remaining part was placed in the big portfolio (B). The $\mathrm{S}$ portfolios are organised in increasing order according to their Book-to-Market Value, and the firms presenting a negative value are withdrawn. After sorting the portfolio, the sample is divided into 30\% lower (L), 40\% medium (M) and 30\% higher $(\mathrm{H})$. As a result, the portfolios of firms SL, SM and SH are formed. The procedure is analogous to the Big portfolio, they are constructed with big firms BL, BM, BH. The assets of each portfolio differ according to their market capitalization value. This classification is maintained over a year. The process is repeated in each of the thirteen years of the sample. SMB risk factor is the difference between the average returns of small portfolios and big portfolios, HML risk factor is the difference between the average returns of high book to market $\mathrm{B} / \mathrm{M}$ portfolios for the market minus the average of the returns for low $\mathrm{B} / \mathrm{M}$ portfolios. The construction of the WML risk factor proposed by Carhart (1997) is determined in a similar way to the previous one, however, after the ordering in $\mathrm{S}$ and $\mathrm{B}$ the next one is carried out with the accumulated profitability, generating six portfolios: SL, SM, SW, BL, BM and BW. WML risk factor is the difference between the average returns of two winner portfolios and the average returns of two loser portfolios.

Table 1 shows the descriptive statistics for the portfolios and the risk factors used in all of the sample 4 . It should be noted that the SMB factor is negative in the entire sample indicating that small stocks suffered during the analysed period. The WML risk factor offer positive returns, showing that the returns of past winners are higher than past losers. Moreover, the correlation coefficient between the returns of GRI portfolio and SMB factor is negative.

Table 1: Descriptive statistics for all sample

\begin{tabular}{cccccccc}
\hline \multirow{2}{*}{ Portfolios } & \multirow{2}{*}{ Mean } & \multirow{2}{*}{ Std. } & \multicolumn{6}{c}{ Cross correlation } \\
\cline { 3 - 7 } & & & $R_{m}-R_{f}$ & GRI & SMB & HML & WML \\
\hline$R_{m}-R_{f}$ & 0.003 & 0.544 & 1.000 & & & & \\
GRI & 0.010 & 0.553 & 0.940 & 1.000 & & & \\
SMB & -0.002 & 0.015 & -0.195 & -0.197 & 1.000 & & \\
HML & 0.012 & 0.029 & -0.097 & -0.067 & 0.233 & 1.000 & \\
WML & 0.012 & 0.046 & -0.569 & -0.529 & -0.192 & 0.006 & 1.000 \\
\hline
\end{tabular}

This table reports means and standard deviations of monthly returns of $R_{m}-R_{f}$, GRI, $\mathrm{SMB}, \mathrm{HML}$ and WML portfolios for all ten European stock markets over the period 2001-2013. Correlation coefficients are reported. Number of observations: 156.

\section{Methodology}

The empirical research applies the market and Carhart (1997) four factor models that have been widely used by the financial literature for this type of investments. The

\footnotetext{
${ }^{4}$ Tables with descriptive statistics of each stock market are available upon request.
} 
returns $\mathrm{R}_{i, t}=\ln \left(P_{i, t} / P_{i, t-1}\right)$, where $P_{i, t}$ and $P_{i, t-1}$ are the share prices of the firm $i$ at the end of month $t$ and $t-1$, respectively. The market model, is given by:

$R_{t}^{G R I}-R_{f t}=\alpha+\beta\left(R_{m t}-R_{f t}\right)+\varepsilon_{t}$

where $R_{t}^{G R I}-R_{f}$ and $R_{m t}-R_{f}$, is the excess return on the GRI portfolio and on the market portfolio in month $t$, respectively. The coefficient $\alpha$ is the risk-adjusted return of the GRI portfolio, which indicates how an investment has performed after accounting for the risk it involved. The parameter ${ }^{\beta}$ represents the systematic risk and $R_{f}$ as the risk-free rate.

In order to investigate investment risk factors, the model uses the four-factor model (1997) to analyse the performance of GRI portfolios in the European market as a whole and in each individual market in the period 2001-2013. The model is given by:

$R_{t}^{G R I}-R_{f t}=\alpha+\beta_{m t}\left(R_{m t}-R_{f t}\right)+\beta_{s m b} S M B_{t}+\beta_{h m l} H M L_{t}+\beta_{w m l} W M L_{t}+\varepsilon_{t}$

$S M B_{t}$ is the difference between small and big capitalization stocks for month $t$. HML $L_{t}$ is the difference between the returns on portfolios of high and low book-to-market stocks for month $t . W M L_{t}$ is the difference between the monthly returns on a portfolio long on past one-year winners and short on past one-year losers. The momentum factor is designed to capture the risk due to the momentum found in stock returns by Jegadeesh and Titman (1993). The equations (1) and (2) are estimated in a pooled by Robust Ordinary Least Squares method (ROLS).

\section{Empirical Results and Analysis}

Table 2 shows the results of the ROLS regression for the market model, which consider the entire sample and each market individually over three periods of time: 2001 2013, 2001-2017 (pre-crisis) and 2008-2103 (post-crisis). The results show that the constant $\alpha$ presents a positive and statistically significant value in Denmark and Germany, which means that the GRI portfolio outperformed the market portfolio over the 2001 and 2013 period, except in Sweden where this value is negative. The systematic risk obtains a value significantly lower than one in Denmark and Germany. Thus, we can say that investing in rated firms according to GRI guidelines has outperformed the market portfolio, although it was a riskier investment for Finland, France, Germany Spain and Sweden during the recession period. The GRI portfolio is well explained by the proposed model since it presents an $R^{2}$ coefficient between 84 and 89 percent in the three periods under study. These findings are consistent with other studies (MirallesMarcelo et al. 2012).

The alpha parameter is $7.442 \%$ annually for the entire sample that considers the ten stock markets as a whole, although not statistically significant. Furthermore, the results are statistic and economically significant in the Danish and German stock markets, confirming that firms that disclose information according to GRI guidelines earn 11.35\% and $6.167 \%$ annually, respectively, above average stock market returns. In these cases, the alpha value exhibits positive abnormal returns in comparison with the market portfolio with significance levels of $5 \%$ and $10 \%$, respectively. In Sweden this value is negative with significance levels of $10 \%$, while for the remaining stock markets it is not statistically significant. 
Table 2: Empirical results of Market model

\begin{tabular}{lccccccccc}
\hline Period & \multicolumn{3}{c}{$2001-2013$} & \multicolumn{3}{c}{$2001-2007$} & \multicolumn{3}{c}{$2008-2013$} \\
\hline Market & $a(\%)$ & $R_{m}-R_{f}$ & $A d j R^{2}$ & $a(\%)$ & $R_{m}-R_{f}$ & $A d j R^{2}$ & $a(\%)$ & $R_{m}-R_{f}$ & $A d j R^{2}$ \\
\hline All sample & 7.442 & $0.942^{* * *}$ & 0.923 & $52.862^{* *}$ & $0.765^{* * *}$ & 0.857 & 4.907 & $1.043^{* * *}$ & 0.960 \\
Denmark & $11.350^{* *}$ & $0.690^{* * *}$ & 0.432 & $14.028^{*}$ & $0.458^{* * *}$ & 0.175 & $14.028^{* * *}$ & $0.850^{* * *}$ & 0.655 \\
Finland & 1.206 & $1.096^{* * *}$ & 0.817 & 6.167 & $0.966^{* * *}$ & 0.646 & 0.000 & $1.108^{* * *}$ & 0.928 \\
France & 0.000 & $0.963^{* * *}$ & 0.744 & 0.000 & $0.891^{* * *}$ & 0.681 & 1.206 & $1.028^{* * *}$ & 0.803 \\
Germany & $6.167^{*}$ & $0.859^{* * *}$ & 0.738 & $16.765^{* * *}$ & $0.585^{* * *}$ & 0.582 & -1.206 & $1.164^{* * *}$ & 0.892 \\
Italy & 0.000 & $0.900^{* * *}$ & 0.840 & 1.206 & $0.669^{* * *}$ & 0.652 & 0.843 & $0.969^{* * *}$ & 0.916 \\
Netherlands & 1.206 & $0.825^{* *}$ & 0.749 & 1.814 & $0.692^{* * *}$ & 0.599 & 3.908 & $0.891^{* * *}$ & 0.842 \\
Norway & 0.000 & $0.737^{* * *}$ & 0.688 & $11.616^{* *}$ & $0.326^{* * *}$ & 0.284 & -6.167 & $0.945^{* * *}$ & 0.897 \\
Spain & 0.000 & $0.967^{* * *}$ & 0.859 & 1.814 & $0.752^{* * *}$ & 0.748 & 1.206 & $1.040^{* * *}$ & 0.908 \\
Sweden & $-3.569^{*}$ & $1.035^{* *}$ & 0.893 & $-12.682^{* *}$ & $1.239^{* * *}$ & 0.706 & $-3.288^{*}$ & $1.040^{* * *}$ & 0.974 \\
UK & 0.000 & $0.828^{* * *}$ & 0.833 & $6.548^{* *}$ & $0.571^{* * *}$ & 0.680 & $-4.907^{*}$ & $0.932^{* * *}$ & 0.929 \\
\hline
\end{tabular}

This table shows the results from regressing equation (1) of monthly returns for GRI portfolios. The market model was applied on all of the sample and on each market individually by subperiods from 2001 to 2013. The values of the adjusted $R^{2}$ are presented in the table ${ }^{* * *},{ }^{* *}$ and ${ }^{*}$ represent significance levels of $1 \%, 5 \%$, and $10 \%$, respectively. Sample alphas are annualised percentages. The Jarque-Bera test was performed and the p-value obtained is significant in all cases. Number of observations: 156. Number of observations: 84 and 72 in 2001-2007 and 2008-2013 periods, respectively.

Table 3: Empirical results of Carhart model by period

\begin{tabular}{|c|c|c|c|c|c|c|c|}
\hline Market & Period & $a(\%)$ & $R_{m}-R_{f}$ & SMB & HML & WML & $\operatorname{Adj} R^{2}$ \\
\hline \multirow{3}{*}{ All markets } & $2001-2013$ & -19.561 & $0.976^{* * *}$ & -0.643 & $0.827^{* *}$ & $1.085^{* * *}$ & 0.926 \\
\hline & 2001-2007 & 18.156 & $0.805^{* * *}$ & -1.461 & 0.785 & 0.581 & 0.864 \\
\hline & 2008-2013 & -2.426 & $1.092^{* * *}$ & 1.017 & -0.397 & $1.274^{*}$ & 0.963 \\
\hline \multirow{3}{*}{ Denmark } & 2001-2013 & $11.350^{* *}$ & $0.706^{* * *}$ & $-0.002^{*}$ & 0.000 & $-0.002^{* * *}$ & 0.500 \\
\hline & 2001-2007 & $18.156^{* *}$ & $0.407^{* * *}$ & -0.001 & $-0.003^{* * *}$ & 0.000 & 0.330 \\
\hline & 2008-2013 & $12.682^{* *}$ & $0.821^{* * *}$ & $-0.002^{*}$ & 0.000 & $-0.002^{* * *}$ & 0.718 \\
\hline \multirow{3}{*}{ Finland } & 2001-2013 & 0.000 & $1.102^{* * *}$ & $-0.002^{*}$ & 0.000 & $-0.001^{*}$ & 0.837 \\
\hline & 2001-2007 & $8.731^{*}$ & $0.874^{* * *}$ & 0.000 & -0.002 & -0.001 & 0.685 \\
\hline & 2008-2013 & -1.206 & $1.230^{* * *}$ & $-0.004^{* * *}$ & 0.000 & $0.001^{* * *}$ & 0.932 \\
\hline \multirow{3}{*}{ France } & 2001-2013 & -2.426 & $0.973^{* * *}$ & $-0.007^{* * *}$ & 0.001 & $0.001^{* * *}$ & 0.837 \\
\hline & 2001-2007 & -2.426 & $1.059^{* * *}$ & $-0.005^{* * *}$ & 0.000 & $0.002^{* * *}$ & 0.761 \\
\hline & 2008-2013 & -1.206 & $0.889^{* * *}$ & $-0.008^{* * *}$ & 0.000 & 0.000 & 0.917 \\
\hline \multirow{3}{*}{ Germany } & 2001-2013 & -2.426 & $0.876^{* * *}$ & $-0.007^{* * *}$ & $0.001^{* * *}$ & $0.001^{* * *}$ & 0.847 \\
\hline & 2001-2007 & $7.442^{*}$ & $0.738^{* * *}$ & $-0.005^{* * *}$ & 0.000 & 0.001 & 0.764 \\
\hline & $2008-2013$ & $-8.731^{* * *}$ & $1.003^{* * *}$ & $-0.007^{* * *}$ & $0.001^{*}$ & 0.001 & 0.934 \\
\hline \multirow{3}{*}{ Italy } & 2001-2013 & 1.206 & $0.870^{* * *}$ & $-0.004^{* * *}$ & $0.001^{* * *}$ & 0.000 & 0.896 \\
\hline & 2001-2007 & 1.206 & $0.692^{* * *}$ & $-0.002^{* *}$ & 0.001 & 0.000 & 0.711 \\
\hline & 2008-2013 & 2.426 & $1.023^{* * *}$ & $-0.006^{* * *}$ & -0.000 & 0.000 & 0.952 \\
\hline \multirow{3}{*}{ Netherlands } & 2001-2013 & 0.000 & $0.838^{* * *}$ & 0.000 & 0.000 & 0.000 & 0.755 \\
\hline & 2001-2007 & 0.000 & $0.763^{* * *}$ & 0.000 & 0.000 & 0.000 & 0.622 \\
\hline & 2008-2013 & 2.426 & $0.860^{* * *}$ & -0.001 & $-0.001^{* *}$ & 0.000 & 0.855 \\
\hline \multirow{2}{*}{ Norway } & $2001-2013$ & 0.000 & $0.762^{* * *}$ & $-0.001^{* *}$ & 0.000 & $0.001^{* * *}$ & 0.717 \\
\hline & 2001-2007 & 6.167 & $0.422^{* * *}$ & 0.000 & 0.000 & $0.001^{* * *}$ & 0.387 \\
\hline
\end{tabular}




\begin{tabular}{cccccccc}
\multirow{4}{*}{ Spain } & $2008-2013$ & 0.000 & $0.883^{* * *}$ & $-0.003^{* * *}$ & 0.000 & -0.001 & 0.922 \\
& $2001-2013$ & $-3.569^{* *}$ & $0.707^{* * *}$ & $-0.004^{* * *}$ & $0.001^{* * *}$ & $0.000^{* *}$ & 0.938 \\
& $2001-2007$ & -1.206 & $0.972^{* * *}$ & $-0.005^{* * *}$ & 0.000 & 0.000 & 0.861 \\
\multirow{3}{*}{ Sweden } & $2008-2013$ & $-3.659^{*}$ & $0.949^{* * *}$ & $-0.004^{* * *}$ & $0.002^{* * *}$ & $0.000^{*}$ & 0.963 \\
& $2001-2013$ & 0.000 & $0.978^{* * *}$ & $-0.002^{* * *}$ & $0.001^{* * *}$ & -0.003 & 0.912 \\
& $2001-2007$ & -3.659 & $1.141^{* * *}$ & $-0.005^{* * *}$ & 0.000 & $-0.002^{* *}$ & 0.763 \\
\multirow{3}{*}{ UK } & $2008-2013$ & 0.000 & $1.006^{* * *}$ & -0.002 & 0.000 & $-0.001^{* * *}$ & 0.986 \\
& $2001-2013$ & 0.000 & $0.883^{* * *}$ & $-0.005^{* * *}$ & $0.001^{* * *}$ & -0.004 & 0.875 \\
& $2001-2007$ & 4.907 & $0.663^{* * *}$ & $-0.003^{* *}$ & 0.002 & 0.000 & 0.70 \\
& $2008-2013$ & -1.206 & $0.981^{* * *}$ & $-0.005^{* * *}$ & 0.000 & 0.000 & 0.953 \\
\hline
\end{tabular}

This table shows the results from regressing equation (2) of monthly returns for GRI portfolios. The explanatory variables are Rm-Rf, GRI, SMB, HML and WML. These variables are designed to capture market, size, book-to-market and momentum effects, respectively, using robust ordinary least squares in the entire sample and by each market in the subperiods 2001 to 2013. The values of the adjusted $R^{2}$ are presented in the table ${ }^{* * *},{ }^{* *}$ and ${ }^{*}$ represent significance levels of $1 \%, 5 \%$, and $10 \%$ respectively. Sample alphas are annualised percentages.

Unlike the stock market in Sweden where this investment strategy does not obtain better value in relation to the market portfolio, in this case the GRI portfolio underperformed the market in $3.569 \%$ annually. Investing in SR firms is riskier than investing in the market portfolio only in Finland and Sweden. The models for each stock market have a high explanatory power that ranges from $43,2 \%$ in Denmark and reaches its maximum value when considering the entire sample with $92.3 \%$.

Table 3 presents the results for the four-factor model regressions and clearly shows us the differences amongst European markets. As we can observe, for both, all markets and for most of the markets considered, the risk-adjusted return is significantly different from zero in Denmark, Finland, Germany and Spain, but depends on the period considered. Nonetheless, significant out-performance can only be found in Denmark where this value is positive, which means that investing in SR Danish firms rated by GRI has won when compared with their market portfolio. In this country, this investment strategy achieves a significantly positive risk-adjusted return, unlike Spain where the value is negative and this type of investment is penalised. Moreover, in the fourth column all the coefficients that represent the exposure to the market factor are statistically significant at the 1\% level and less than one in Denmark, Netherlands, Norway, Spain and UK, as it implies that investing in a GRI portfolio is less risky when compared to investing in the respective market in any of the time periods. However, for the remaining markets it depends on the period under study, and after 2008, SRI investment is riskier in all of the sample and also in Finland, Germany, Italy and Sweden.

Lastly, results in Table 3 show that market factor is not similar in pre and post crisis periods. Hence, the risk of GRI portfolios changes substantially across the whole sample and in each stock market. At first glance, results for size exposure, provide some understanding that investors prefer the bigger GRI stocks in France, Germany, Italy, Spain and UK, while in Denmark, Finland, Norway and Sweden it depends on the period of time, in the remaining markets the size factor is not statistically significant. The results show us that the coefficient SMB is statistically significant at the $1 \%$ level for 
most European countries. For HML effect, the sample for Germany, Italy, Spain, Sweden and UK have significant positive values, which means that the loadings suggest that the high-level GRI portfolio was growing during the period from 2001 to 2013. For the WML factor, only negative has a significantly higher effect for Denmark, Finland and Sweden. The adjusted $\mathrm{R}^{2}$ from the models has increased and proves the incremental explanatory power of a multivariate framework.

\section{Conclusion}

The aim of this research is to investigate the effect of Socially Responsible Investment in terms of return and risk in the most prominent European markets. The sample includes all listed firms as well as all of the industries, except the financial sector; thus, the study represents a sample of the real situation of each stock market, into a timeframe of more than one decade which comprises the global financial crisis. The research applies two regression models to establish the relationship between firms rated by the GRI and the market portfolio. Considering the economic specificity of each European market analysed, although not all of them reacted equally to the economic crisis, the analysis is carried out by applying the methodology proposed to each of the ten European markets individually in the pre and post crisis subperiods.

Nevertheless, this study shows that the majority of firms still do not disclose information according to GRI guidelines. The portfolios of SRI have a significant impact on stock returns in Denmark and Germany and in the expansion period in Finland and Germany, but for the remaining markets the alphas do not capture SRI effects. This type of investing is less risky than investing in the market portfolio in most of the European stock markets. The results of this study make several contributions to the existing literature on SRI and show that the behaviour of investors differs from country to country. The nature of SRI leads to a reduction in the number of firms that can be selected for the investment portfolio thereby reducing their diversification potential.

A limitation of this study is to obtain financial information for all of the firms listed on the GRI, because not all of them are available in DataStream. Research will continue in order to analyse European stock markets by considering the particularities of each sector of activity.

\section{Acknowledgement}

The author thanks to the Lisbon Polytechnic Institute for financially supporting this project under the Research, Development, Innovation and Artistic Creation Project 2017 referenced by IPL/2017/GIIPS5/ISCAL), this paper is part of it. Special acknowledgment to GRI for providing data.

\section{References}

Brzeszczynski, J. \& McIntosh, G. (2014). Performance of Portfolios Composed of British SRI Stocks. Journal Business Ethics, 120, 335-362.

Carhart, M. M. (1997). On persistence in mutual fund performance. Journal of Finance, 52 (1), 57-82. 
Derwall, J., K. Koedijk \& J. T. Horst (2011). A tale of values-driven and profit-seeking social investors. Journal of Banking \& Finance, 35 (8), 2137-2147.

Eurosif (2014). European SRI Study 2012. Eurosif, Paris.

Fama, E. \& K. French, (1993). Common risk factors in the returns of stocks and bonds. Journal of Financial Economics, 33 (1), 3-56.

Galema, R., Plantinga, A. \& Scholtens, B. (2008). The stocks at stake: Return and risk in socially responsible investment. Journal of Banking and Finance, 32, 1646-1654.

Griffin, J. J. \& Mahon, J. F., (1997). The Corporate Social Performance and Corporate Financial Performance Debate: Twenty-Five Years of Incomparable Research, Business \& Society, 36 (5), 5 31.

Hong, H. \& Kacperczyk, M. (2009). The price of sin: The effects of social norms on markets. Journal of Financial Economics, 93, 15-36.

Humphrey, J. E., Lee, D.. \& Shen, Y. (2012). Does it cost to be sustainable?. Journal of Corporative Finance, 18 (4), 626-639.

Jackson, G. \& Apostolakou, A. (2010). Corporate social responsibility in Western Europe: a institutional mirror or substitute. Journal of Business Ethics, 94 (3), 371-394.

Kempf, A. \& Osthoff, P. (2007). The effect of socially responsible investing on portfolio performance. European Financial Management, 13 (5), 908-922.

KPMG (2015), International Survey of Corporate Responsibility Reporting 2015, KPMG Internacional, Netherlands.

Miralles-Marcelo, J., Miralles-Quirós, M. \& Miralles-Quirós, J. (2012). Performance Bursátil de las Empresas Socialmente Responsables, Cuadernos de Economía y Dirección de la Empresa, 15, 221-230.

Mollet, J.C. \& Ziegler, A. (2014). Socially responsible investing and stock performance: New empirical evidence for the US and European stock markets, Review of Financial Economics, 23 (4), 208-216.

Revelli, C. \& Vivianni, J. L. (2015). Financial performance of socially responsible investing (SRI): what have we learned? A meta-analysis, Business Ethics: A European Review, 24 (2), 158-185.

Scholtens. B. (2006). Finance as a driver of corporate social responsibility. Journal of Business Ethics, 68, 19-33. DOI: $10.1007 / \mathrm{s} 10551-006-9037-1$.

Statman, M. \& Glushkov, D. (2009). The wages of social responsibility, Financial Analysts Journal, 65 (4), 33 46.

Trinks, P. \& Scholtens, B. (2017). The Opportunity Cost of Negative Screening in Socially Responsible Investing. Journal of Business Ethics, Available on doi: 10.1007/s10551-015-2684-3.

Renneboog, L., Horst, J. \& Zhang, C. (2008). The price of ethics and stakeholder governance: the performance of socially responsible mutual funds, Journal of Corporate Finance, 14, (3), 302-322.

Waddock, S. A. \& Graves, S. (1997). The corporate social performance-financial performance link, Strategic Management Journal, 18, (4), 303-319.

Wallis, M. \& Klein, K. (2015). Ethical requirement and financial interest: a literature review on socially responsible investing, Business Research, 8, 61-98.

Wang, Q., Dou, J. \& Jia, S. (2016). A meta-analytic review of corporate social responsibility and corporate financial performance: the moderating effect of contextual factors, Business \& Society, 55 (8) 1083-1121. 